Malkus which provides a detailed and coheront picture of the present position in this field. Interaction probloms are classified into: (I) formally tractable dynamical problems such as wind-driven ocean currents : (2) conservation studies of sources and transport of energy and solutes, for particular ocean basins, for example; (3) statistical analysis of observational data; (4) descriptivo studies relying largely on physical analogues. Many recent investigations of the heat and water exchange between the atmosphere and oceans are discussed and rolated to climatological and general circulation studies.

Of particular interest to all workors in geophysical subjects will be the stimulating and critical concluding remarks by Dr. Malkus concerning the direction which our futuro effort must take. In particular, attention is directed to the necessity for "growth in the fundamental physics of turbulent, heat-driven fluids" and the noed to pose questions which ". . . isolate tractable foatures of the complexity which can be treated undor relativoly controlled conditions". The scientific and economic background to all geophysical investigations, including oceanography, depends on the answer to her final question ". . . concerning what do we need more and better data the most ?". It would have been most rofreshing if more contributors had taken advantage of the sub-title of the book to take such a critical look at thoir branches of the subject.

The reader is certain to bo impressed by the growing stature of physical oceanography as a seientific discipline. Although basically an observational science, the growing numbers of theoroticians and experimenters which it has attracted are responsible for many now and valuable fields of investigation. The editors and publishers must be congratulated on this worthwhile enterprise; tho remaining volumes will bo eagerly awaited.

J. N. HuNT

\section{MATHEMATICAL ANALYSIS OF TRANSIENT CIRCUITS}

Transient Circuit Analysis

By Prof. Y. H. Ku. (The Van Nostrand Series in Elec. tronics and Communications.) Pp. xiv +441 . (Princeton, N.J.: D. Van Nostrand Company, Inc.; London: D. Van Nostrand Company, Ltd., 1961.) 79s.

$T^{1}$ HE importance of circuit analysis is reflected in the great number of books on this subject, especially those emanating from the United States. It is of some interest to compare the present book with another book on the same subject, also by an American professor, written about a decade ago.

Both books cover roughly the samo ground, including Maxwell's and Kirchhoff's rules, Fourier series, integral and transform, Laplace and Heaviside transforms, complex variable and inverse transform, Bessel, gamma and error functions. There is also in both books a fairly full treatment of the transmission line.

The great difference between the two books lies in the authors' approach to the subject. In the earlier book the author is concerned to demonstrate to electrical engineers the importance of mastering advanced mathematical techniques in order to solve engineering problems. The book is well supplied with practical problems, the initial approach is more elementary and some of the more difficult mathematical proofs are omitted, the reader being given references to mathematical works. In the present book the author's approach is frankly mathematical, and ho clearly has supremo confidence in the mathematical outlook and training of tho modern electrical engineer. In an introductory chapter the author appears concerned to show that engineering problems do exist to which the mathematical techniques may bo applied. Thereafter the work is mainly mathematical and one almost expects an asterisk to the first chapter with a footnote saying that this chapter may be omitted on a first reading. References are given throughout the book to other works, but the author has aimed at making his book as self-contained as possible and has included in appendixes reprints from original papers.

The symbols used are generally well chosen, but the British Standards Institution might be somewhat distressed at the apparent dimensional error in the equation:

$$
L \frac{\mathrm{d} i}{\mathrm{~d} t}+R_{0} i^{2}+S \int i \mathrm{~d} t=e
$$

Tho author states not very far away that $\left(R_{0} i\right)$ is a resistance, but his demonstration of a non-linear equation could have been made without this unsatisfactory symbolism by writing the equation as:

$$
L \frac{\mathrm{d} i}{\mathrm{~d} t}+\left(\frac{R_{11}}{I}\right) i^{2}+S \int i \mathrm{~d} t=e
$$

where $I$ is a constant, having the dimensions of a cur. rent.

The author's treatment of the solution of differential equations is satisfying both in its adequacy and freedom from unnecessary complications. The inclusion of methods of solving cubic, quartic and quintic equations is an attractive feature.

The square wave is in the forefront of the Fourier analysis of periodic waves, but although the author gives the Dirichlet conditions for satisfactory analysis, he makes no reference to Gibbs's spike and presumably considers that since the spike does not affect the standard deviation it can safely be ignored. This possibly illustrates a difference betwoon the mathematical ongineor of to-day and the more practical-minded engineer of yesterday, but it seems regrettable that a defect in Fourier analysis, exposed moro than sixty years ago, should be in danger of being forgotten by our present-day mathematicians. Gibbs's spike can, of course, be eliminated quite easily by changing the shape of the periodic wave from a squaro wave, which cannot bo realized in practice, to any approximation to a square wave which has no discontinuity.

This minor criticism apart, the book is an excellent toxt-book on a difficult subject. It is intended for graduates and would be too advanced for most undergraduates.

\section{A. H. M. ARNOLD}

\section{SCIENCE FOR THE MODERN WORLD}

Chemistry, Physics and Biology for the Modern World Chemistry. By Prof. George Porter. Pp. ix +116. Physics for the Modern World. By Prof. E. N. da C. A.ndrade. Pp. viii +100 . Biology for the Modern World. By Prof. C. H. Waddington. Pp. ix +120 . (Science for the Modern World Series, Vols. 1, 2 and 3.) (London: George G. Harrap and Co., Ltd., 1962.) 4s. 6d. each volume.

7 HERE are severe problems in writing a chemistry, physics or biology book which in the span of some hundred pages must cover the basic theories, techniques and technologies of the subject. Accepting the necessity to solve the problem, these three books are regarded as a fine attempt.

Their presentation is attractive, their English is direct, their diagrams clear and useful, and they are served by a very full index.

The chemistry book deals with atomic theory, the characteristics of common olements, their atomic structure and the shape of the molocules they form. The kinetic theory is introduced and used for explaining the strates of 